Revista Universo Contábil, ISSN 1809-3337

Blumenau, v. 9, n. 2, p. 83-103, abr./jun., 2013

doi:10.4270/ruc.2013214

Disponível em www.furb.br/universocontabil

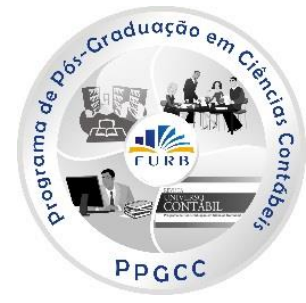

CONSERVADORISMO CONDICIONAL NA INDÚSTRIA BANCÁRIA BRASILEIRA EM SITUAÇÕES DE MAIOR PERCEPÇÃO DE RISCO'

\title{
CONDITIONAL CONSERVATISM IN THE BRAZILIAN BANKING INDUSTRY IN SITUATIONS OF HIGHER RISK PERCEPTION
}

\section{CONSERVADURISMO CONDICIONAL EN LA INDUSTRIA BANCARIA BRASILEÑA EN SITUACIONES DE MAYOR PERCEPCIÓN DE RIESGO}

José Alves Dantas

Doutor em Ciências Contábeis pela Universidade de Brasília - UnB

Professor Adjunto I da Universidade de Brasília - UnB Endereço: Quadra 105, Lote 8, Apto. 501, Águas Claras

CEP: 71915-250 - Brasília - DF

E-mail: josealvesdantas@gmail.com

Telefone: (61) 8406 -9524

Edilson Paulo

Doutor em Ciências Contábeis pela Universidade de São Paulo - USP

Professor Adjunto III da Universidade Federal da Paraíba

Endereço: Departamento de Contabilidade e Finanças - DFC/CCSA

Campus Universitário I CEP: 58.059-900 - João Pessoa - PB

E-mail: e.paulo@uol.com.br

Telefone: (83) 3216-7285

Otávio Ribeiro De Medeiros

Doutor em Economia pela Universidade de Southampton, Reino Unido

Professor Titular da Universidade de Brasília - UnB Endereço: SQN 205, Bloco C, apto 401, Asa Norte

CEP: 70843-030 - Brasília - DF

E-mail: otavio@unb.br

Telefone: (61) 9978-9503

\section{RESUMO}

Estudos sobre o conservadorismo condicional, que pressupõe uma assimetria no reconhecimento de boas e más notícias nos resultados, são relativamente comuns na literatura

\footnotetext{
1 Artigo recebido em 25.06.2012. Revisado por pares em 19.02.2013. Reformulado em 30.05.2013. Recomendado para publicação em 07.06.13 por Carlos Eduardo Facin Lavarda. Publicado em 30.06.2013. Organização responsável pelo periódico: FURB.
} 
José Alves Dantas - Edilson Paulo - Otávio Ribeiro De Medeiros

contábil, tanto em âmbito internacional como nacional. Os que examinam essa prática no âmbito da indústria bancária, porém, são recentes e escassos. $\mathrm{O}$ presente artigo procura contribuir para preencher essa lacuna, tendo como propósito verificar se os resultados contábeis dos bancos brasileiros registram evidências de conservadorismo condicional e, mais especificamente, se essa prática pode ser associada a situações de maior percepção de risco. Para a realização dos testes empíricos foram utilizados os dados das informações financeiras trimestrais dos bancos comerciais, bancos múltiplos e caixas econômicas, entre 2001 e 2010 . As proxies representativas das situações de maior percepção de risco foram construídas em função dos períodos caracterizados como de risco sistêmico, do Índice de Basileia e do nível de capitalização contábil dos bancos. As evidências obtidas confirmaram, inicialmente, a premissa de assimetria no reconhecimento das boas e más notícias, com o diferimento dos ganhos econômicos e reconhecimento mais tempestivo das perdas, corroborando a hipótese de conservadorismo condicional nos resultados contábeis dos bancos brasileiros. Não foi confirmada a expectativa de aumento dessa prática em momentos definidos como de risco sistêmico e por parte de bancos com menor Índice de Basileia. Quando a proxy de situação de risco é baseada no nível de capitalização eminentemente contábil, porém, os testes revelaram associação negativa entre o reconhecimento mais tempestivo das perdas econômicas e o nível de participação do capital próprio na estrutura de capitais das instituições.

Palavras-chave: Conservadorismo Contábil; Bancos; Riscos; Ganhos e Perdas; Resultados.

\section{ABSTRACT}

Studies on conditional conservatism, which assumes asymmetry in the recognition of good and bad news on earnings, are relatively usual in the accounting literature, both internationally and nationally. However, those examining this practice within the banking industry are recent and scarce. This paper attempts to contribute to fill this gap by aiming at verifying whether the accounting earnings of Brazilian banks show evidence of conditional conservatism and, more specifically, whether this practice can be associated to situations of higher risk perception. For performing empirical tests, we use data from the quarterly financial information of commercial, multiple and savings banks from 2001 to 2010. The proxies representing situations of higher risk perception are constructed taking into account periods presenting systemic risk in terms of the Basel Index and the level of capitalization of banks. The evidence obtained confirm the assumption of asymmetry in the recognition of good and bad news, with the postponement of economic profits and the immediate recognition of losses, which corroborates the hypothesis of conditional conservatism in the accounting earnings of Brazilian banks. Expectations towards an increase of this practice in periods of systemic risk and by banks with a lower Basel Index are not confirmed. Yet, when the proxy of a risky situation is based on the book value of capitalization, the tests show a negative association between the timely recognition of economic losses and the level of participation of equity in the capital structure of the institutions

Keywords: Accounting Conservatism; Banks; Risk; Profits and Losses; Earnings.

\section{RESUMEN}

Los estudios sobre el conservadurismo condicional, que presuponen una asimetría en el reconocimiento de buenas y malas noticias en los resultados son relativamente comunes en la literatura contable, tanto a nivel internacional y nacional. Aquellos que examinan esta práctica en la industria bancaria, sin embargo, son recientes y escasos. Este artículo pretende contribuir a llenar esta carencia, con el propósito de verificar si los resultados contables de los bancos brasileños registran evidencia de conservadurismo condicional y, 
más concretamente, si esta práctica puede ser asociada a situaciones de mayor percepción de riesgo. Para la realización de las pruebas empíricas fueran utilizados los datos de las informaciones financieras trimestrales de los bancos comerciales, bancos múltiples y cajas de ahorros entre 2001 y 2010. Las proxies que representan situaciones de mayor percepción de riesgo se construyó de acuerdo con los períodos que se caracterizaran como de riesgo sistémico, con base en el Índice de Basilea y en el nivel de capitalización contable de los bancos. Las evidencias obtenidas confirman la premisa de asimetría en el reconocimiento de buenas y malas noticias, con el aplazamiento de las ganancias y reconocimiento más tempestivo de las pérdidas económicas, lo que apoya la hipótesis del conservadurismo condicional en los resultados contables de los bancos brasileños. No se confirmó la expectativa de aumento en esta práctica en periodos de riesgo sistémico, y por los bancos con menor Índice de Basilea. Cuando la proxy de situación de riesgo se basa en el nivel de capitalización eminentemente contable, sin embargo, los análisis revelaron una asociación negativa entre el reconocimiento más oportuno de las pérdidas económicas y el nivel de participación del capital proprio en la estructura de capital de las instituciones.

Palabras clave: Conservadurismo Contable; Bancos; Riesgo; Ganancias y Pérdidas; Resultados.

\section{INTRODUÇÃO}

Historicamente, o conservadorismo integra os princípios, convenções ou características qualitativas da informação contábil. Notadamente a partir da consolidação dos padrões contábeis sugeridos pelo International Accounting Standards Board (IASB), em que a adoção do valor justo é uma das principais referências de mensuração de ativos e passivos, acentuaram-se os debates sobre as vantagens e as desvantagens do conservadorismo contábil (LAUX; LEUZ, 2009; DECHOW; GE; SCHRAND, 2010; TAPIA et al., 2011). No centro dessa discussão, situa-se a eventual incompatibilidade entre o conservadorismo e a neutralidade da informação contábil. Esse, aliás, foi o argumento adotado pelo IASB para excluir o conservadorismo das características qualitativas da informação contábil, na revisão da sua estrutura conceitual, replicada no Brasil por meio de manifestação do Comitê de Pronunciamentos Contábeis (CPC, 2011).

Embora nos preceitos normativos prevalecesse a forma de conservadorismo incondicional, que conduzia à subavaliação sistemática do patrimônio, a partir do estudo seminal de Basu (1997) o conservadorismo condicional, que pressupõe uma assimetria no reconhecimento de boas e más notícias nos resultados, ganhou força nos estudos acadêmicos.

A partir de então, não obstante as discussões sobre a sua pertinência e os pronunciamentos dos reguladores, vários estudos têm destacado o conservadorismo como uma importante propriedade dos resultados contábeis, tanto em âmbito internacional (GIVOLY; HAYN, 2000; BEAVER; RYAN, 2000; AHMED; et al., 2002; BALL; SHIVAKUMAR, 2005; LaFOND; WATTS, 2008; ERKENS; SUBRAMANYAM; ZHANG, 2011; por exemplo) quanto no mercado brasileiro (COSTA; COSTA; LOPES, 2006; COELHO; LIMA, 2007; SANTOS; COSTA, 2008; PAULO; ANTUNES; FORMIGONI, 2008; KAIZER; et al., 2008; GONZAGA; COSTA, 2009; MOREIRA; COLAUTO; AMARAL, 2010; entre outros).

De acordo com Watts (2003a) e Tapia et al. (2011), esses estudos têm avançado em diferentes explicações para a existência do conservadorismo, mas as principais são as relações contratuais (teoria dos contratos) e o risco de litigância, em especial de investidores que se sintam prejudicados por informações produzidas a partir de um cenário excessivamente otimista. Em situações dessa natureza, o conservadorismo funcionaria como instrumento para 
o fornecimento de informações mais confiáveis aos investidores e credores, devido a maior exigência de verificabilidade dos ganhos do que para as perdas.

Apesar de serem relativamente comuns estudos que avaliam o conservadorismo praticado pelas empresas, os que se concentram especificamente na indústria bancária são recentes e escassos (NICHOLS; WAHLEN, WIELAND, 2009; TAPIA; et al., 2011). Nichols, Wahlen e Wieland (2009), Lima, Fonseca e Brito (2009) e Tapia et al. (2011) são alguns dos poucos exemplos do gênero, enquanto, no Brasil tem-se o trabalho de Brito, Lopes e Coelho (2008). Considerando o papel vital da intermediação financeira desempenhado pelos bancos para o funcionamento da economia de forma geral, em que um eventual problema de insolvência afeta os demais setores econômicos, seria natural uma maior preocupação dos pesquisadores sobre essa prática contábil na indústria bancária.

Ademais, como os bancos são submetidos a um ambiente de forte regulação e supervisão, conforme destacado por Levine (2004), é razoável supor que os seus administradores utilizem as escolhas contábeis para reduzir a exposição ao risco de um escrutínio por parte do regulador/fiscalizador, mediante a prática do conservadorismo condicional. Esse ambiente de indução ao conservadorismo é reforçado pelo cenário de recorrência de situações de crise nos mercados financeiros e de capital, inclusive em escala global, com questionamentos em relação aos administradores das instituições (LAUX; LEUZ, 2009).

Cabe ressaltar, porém, que se essas situações de maior percepção de risco podem funcionar como argumentos para a administração adotar o conservadorismo condicional, de forma a se proteger de questionamentos por parte do regulador, também podem funcionar como incentivos para escolhas contábeis mais agressivas, com o propósito de demonstrar uma situação financeira mais favorável. Assim, uma mesma condição, a percepção de risco, pode funcionar como incentivo ou restrição para escolhas contábeis, por parte dos administradores das instituições bancárias, que caracterizem o conservadorismo ou a agressividade na divulgação financeira.

Nesse contexto, o presente estudo tem por objetivo verificar se os resultados contábeis na indústria bancária brasileira registram evidências de conservadorismo condicional e, mais especificamente, se essa prática pode ser associada a situações de maior percepção de risco. Para esse propósito, são utilizados como proxies das situações de percepção de risco os períodos considerados como de risco sistêmico, o Índice de Basileia e o nível de capitalização dos bancos, em associação com os modelos de Basu (1997) e de Ball e Shivakumar (2005), para avaliar empiricamente a prática do conservadorismo condicional das instituições bancárias. Os testes são realizados com base nos dados das Informações Financeiras Trimestrais (IFT) dos bancos comerciais, bancos múltiplos e caixas econômicas em atuação no mercado brasileiro, entre 2001 e 2010, disponíveis na página do Banco Central do Brasil (BCB) na internet.

Como contribuição para o avanço da literatura, o presente estudo amplia o conhecimento sobre o conservadorismo contábil no âmbito dos sistemas bancários, e no mercado brasileiro em particular, além de fornecer elementos para a avaliação dessa prática em situações de maior percepção de risco e discutir a eventual dualidade de incentivos/restrições para escolhas contábeis que caracterizem o conservadorismo ou a agressividade no processo de divulgação financeira.

Além desta parte introdutória, o trabalho contempla, nas seções subsequentes: uma revisão da literatura sobre o tema, com destaque para os potenciais incentivos para a prática do conservadorismo contábil e para os estudos que se concentraram nos sistemas bancários (Seção 2); a formulação e desenvolvimento das hipóteses de pesquisa (Seção 3); a especificação dos procedimentos metodológicos utilizados para os testes empíricos, incluindo a definição do modelo econométrico e os parâmetros de análise (Seção 4); a apuração e a 
análise dos resultados (Seção 5); e as conclusões do estudo (Seção 6), tendo por referência a associação entre a fundamentação teórica e os dados empíricos apurados.

\section{REFERENCIAL TEÓRICO}

Como suporte teórico ao desenvolvimento do estudo, nesta Seção são discutidos: os aspectos conceituais do conservadorismo contábil, incluindo as formas com que pode ser compreendido - incondicional e condicional; os incentivos para a prática do conservadorismo contábil pelas organizações; e as pesquisas que avaliaram o conservadorismo nas informações financeiras de instituições bancárias.

\subsection{Conservadorismo Contábil}

Não obstante as críticas quanto à sua eventual incompatibilidade com a característica qualitativa da neutralidade da informação contábil, a utilidade do conservadorismo também é defendida na literatura. Watts (2003a, 2003b), por exemplo, afirma que tentativas de proibir o conservadorismo, a fim de atingir a "neutralidade da informação", sem entender as razões pelas quais tal preceito surgiu e prosperou, tendem a falhar e produzir consequências inesperadas. Para o autor, pesquisadores e reguladores que propõem a capitalização não verificável dos fluxos de caixa futuros nas demonstrações financeiras devem considerar os custos gerados por essa proposta sobre o comportamento dos gestores, o que pode impor custos significativos aos investidores e à economia em geral. Lopes (2002), por sua vez, destaca que o objetivo do conservadorismo é fornecer informações mais confiáveis aos investidores, dado que as demonstrações excessivamente otimistas seriam evitadas.

De forma geral, o conservadorismo contábil, conforme Ball, Kothari e Robin (2000), pode ser compreendido de duas formas: (i) o conservadorismo incondicional, ex-ante ou conservadorismo patrimonial, definido como a subavaliação sistemática do patrimônio, independentemente dos sinais de prováveis perdas econômicas - entre diferentes alternativas de avaliação, deve-se utilizar a que representa o menor valor atual para ativos e receitas e maiores valores para passivos e despesas; e (ii) o conservadorismo condicional, ex-post ou conservadorismo de resultado, que pressupõe uma assimetria no reconhecimento de boas e más notícias nos resultados - as más notícias são refletidas mais rapidamente que as boas.

Essa segunda forma de conservadorismo, a condicional, adquiriu especial relevância a partir de Basu (1997) e está associada a uma assimetria nos requisitos para o reconhecimento de ganhos e perdas - maiores exigências para reconhecer as boas notícias como lucro do que as más notícias como prejuízo (ERKENS; SUBRAMANYAM; ZHANG, 2011). Com esse tratamento assimétrico, é esperado que os resultados divulgados reflitam perdas econômicas mais tempestivamente que ganhos econômicos (BASU, 1997; BALL; KOTHARI; ROBIN, 2000; BALL; SHIVAKUMAR, 2005).

De acordo com Basu (1997) e Ball e Shivakumar (2005), essa assimetria no reconhecimento de boas e más notícias também se verifica em relação à persistência dos resultados contábeis. Por esse preceito, o reconhecimento das boas notícias é menos oportuno do que o das más notícias. Em compensação, os ganhos associados às boas notícias tendem a ser mais persistentes do que as perdas decorrentes das más notícias. Essa maior persistência dos ganhos se justificaria pelo fato de que as boas notícias se refletem apenas parcialmente no resultado presente, continuando a impactar os lucros dos momentos seguintes. Por outro lado, o reconhecimento oportuno das más notícias significa que a maior parcela das perdas associadas às más notícias é incorporada no resultado presente, configurando a transitoriedade dos efeitos das notícias negativas nos resultados das empresas. Assim, a detecção do conservadorismo se dá pela persistência dos resultados positivos e pela reversão dos componentes transitórios dos resultados negativos. Owens (2011) resume essa relação entre a 
José Alves Dantas - Edilson Paulo - Otávio Ribeiro De Medeiros

persistência assimétrica e a tempestividade assimétrica, ao afirmar que são dimensões interrelacionadas do conservadorismo.

\subsection{Incentivos para o Conservadorismo}

A teoria contábil prevê que o conservadorismo contábil funciona como complemento às condições contratuais na redução do custo de agência, minimizando os conflitos principal-agente (WATTS; ZIMMERMAN, 1986). De forma mais analítica, Basu (1997) e Watts (2003a) ressaltam que entre os fatores que podem justificar/explicar a prática do conservadorismo contábil, podem ser destacados, entre outros: os contratos de remuneração dos administradores; os contratos de dívida; os riscos de ações de litígios por parte de investidores; os efeitos dos tributos incidentes sobre o resultado apurado; e os processos políticos e regulatórios.

De acordo com Brito, Lopes e Coelho (2008), a teoria contratual da firma considera que as relações entre a empresa e os agentes econômicos são feitas por meio de um conjunto de contratos, explícitos ou não. Nesse contexto, de forma a garantir o necessário equilíbrio nas relações contratuais e proteger os interesses econômicos das partes envolvidas, as informações contábeis são utilizadas como suporte ao monitoramento dos contratos entre a empresa e os agentes econômicos. Por esse entendimento, a eficiência das relações contratuais depende essencialmente do acesso dos contratantes às informações contábeis, que complementariam, assim, os mecanismos de governança corporativa.

Tratando especificamente de contratos internos, Watts (2003a) exemplifica esse tipo de situação, ao associar o conservadorismo às relações contratuais da firma, em especial os contratos de remuneração dos administradores. Para o autor, o conservadorismo reduz a probabilidade de a administração superestimar os resultados, evitando distribuições em desacordo com os contratos estabelecidos. Assim, ao restringir a ação oportunista da administração, o conservadorismo aumentaria o valor da firma. Outro exemplo vem da afirmação de Erkens, Subramanyam e Zhang (2011) de que a alavancagem é frequentemente usada como proxy para a demanda por conservadorismo, tendo em vista a lógica de que credores de firmas muito alavancadas demandam mais conservadorismo contábil.

Um aspecto relevante destacado na literatura como argumento para a prática do conservadorismo é o risco de litígios. Considerando que os questionamentos judiciais contra a administração são mais prováveis quando os resultados estão superestimados, configura-se um incentivo para os gestores reportarem resultados mais conservadores (LaFOND; WATTS, 2008; ERKENS; SUBRAMANYAM; ZHANG, 2011). As evidências obtidas por Ball, Kothari e Robin (2000) reforçam essa percepção, ao constatarem o aumento no conservadorismo em ambientes de maior litigância.

Com relação aos tributos incidentes sobre o resultado apurado, de acordo com Watts (2003a), a motivação econômica implícita para a adoção do conservadorismo é a postergação desses tributos. Já em relação aos processos políticos e regulatórios, pode se inferir que setores econômicos mais regulados e fiscalizados têm incentivos para escolhas contábeis mais conservadoras. De acordo com Tapia et al. (2011), por exemplo, a adoção do conservadorismo, em especial o incondicional, pode ser entendida como resultante de demandas regulatórias. Para eles, o conservadorismo tem um papel relevante, especialmente em segmentos regulados como o bancário, funcionando como incentivo para os administradores adotarem práticas mais conservadoras, de forma a evitarem maior escrutínio dos reguladores.

Como síntese dessa discussão, pode-se destacar a afirmação de Tapia et al. (2011), no sentido de que não obstante o avanço da literatura na busca de diferentes explicações para a prática do conservadorismo, as principais são as relações contratuais (teoria dos contratos) e o risco de litigância. Em situações do gênero, o conservadorismo funcionaria como um 
mecanismo de proteção da administração contra questionamentos futuros, coerente com os preceitos defendidos por Watts e Zimmerman (1986).

\subsection{Conservadorismo Contábil na Indústria Bancária}

Conforme já destacado, estudos sobre o conservadorismo são relativamente comuns na literatura contábil. Se forem considerados, porém, apenas os estudos que avaliam essa prática no âmbito da indústria bancária, o estágio da literatura pode ser definido como incipiente. Entre os poucos estudos sobre a prática do conservadorismo contábil pelos bancos podem ser destacados Nichols, Wahlen e Wieland (2009), Lima, Fonseca e Brito (2009) e Tapia et al. (2011) na literatura internacional e Brito, Lopes e Coelho (2008) no mercado brasileiro.

Nichols, Wahlen e Wieland (2009) avaliaram o efeito da estrutura de capitais no conservadorismo condicional, tendo por base uma amostra de bancos comerciais e holdings bancárias norte-americanas, no período de 1992 a 2002. Constataram maior grau de conservadorismo contábil dos bancos com capital aberto que dos bancos com capital fechado. Em síntese, identificaram que os bancos listados em bolsa reconhecem mais tempestivamente as perdas e menos oportunamente os ganhos, quando comparados com os bancos de capital fechado.

Tendo por objeto de estudo o sistema financeiro português, Lima, Fonseca e Brito (2009) analisaram o conservadorismo condicional nos resultados contábeis, entre 2000 e 2007, das instituições bancárias daquele país. Contrariamente ao previsto, os testes empíricos realizados não apresentaram evidências da presença do conservadorismo condicional nos resultados dos bancos. Também não foi confirmada a hipótese de que os bancos de capital aberto registrariam resultados contábeis mais conservadores.

No estudo de Tapia et al. (2011), o propósito foi avaliar os efeitos da exposição dos administradores ao risco de litigância no conservadorismo contábil praticado pela indústria bancária. Os testes empíricos tiveram por base uma amostra de bancos de 69 países, com dados entre 1998 e 2007, e utilizando o nível de capitalização TIER1 (parâmetro de capitalização, definido no Acordo de Basileia, que inclui além das ações ordinárias e lucros retidos, as ações preferenciais, os instrumentos híbridos de capital e as dívidas sem vencimento) como proxy da exposição ao risco de litigância por parte dos administradores dos bancos. Os autores encontraram uma relação negativa entre o nível de TIER1 e o conservadorismo condicional, confirmando as expectativas. A explicação provável para esses resultados é que bancos sujeitos a uma maior vigilância (bancos com menor TIER1) adotem maior grau de conservadorismo condicional, não apenas em uma tentativa de minimizar os custos de litígios, mas também para reduzir a probabilidade de ações políticas regulatórias adversas.

No mercado brasileiro, Brito, Lopes e Coelho (2008) avaliaram a presença do conservadorismo condicional nos resultados contábeis das instituições financeiras, em particular se há diferença entre bancos privados e estatais em relação a essa prática. $\mathrm{O}$ pressuposto considerado é que os gestores dos bancos estatais, pelo fato de estarem sujeitos a um maior controle e exposição legal, teriam incentivos para reportar resultados mais conservadores. Utilizando dados de 276 instituições, compreendendo o período de junho/97 a junho/2007, os autores constataram, inicialmente, não haver evidências de conservadorismo condicional no conjunto das instituições. Entretanto, ao examinar os dois conjuntos de bancos, separadamente, foram encontradas evidências da presença de conservadorismo nos resultados divulgados pelas instituições estatais.

De comum em todos esses estudos sobre o conservadorismo condicional em instituições bancárias há o fato de que utilizaram o mesmo padrão de modelo econométrico para a realização dos testes empíricos de identificação dessa prática contábil. A referência inicial é o modelo dos componentes transitórios do lucro de Basu (1997), cujas premissas 
conceituais são discutidas na Seção 2.1 e que avalia o grau de persistência e de transitoriedade das variações positivas e negativas do resultado contábil. Ball e Shivakumar (2005) ampliaram esse modelo, incluindo variáveis que permitissem identificar a diferença na prática de conservadorismo por parte de companhias abertas e fechadas no Reino Unido. Os estudos citados se inspiraram nesses modelos, com as adaptações óbvias em função das variáveis de interesse que cada um tinha como referência. Também há divergências em relação à utilização ou não de variáveis de controle.

Detalhes sobre a fundamentação desses modelos são apresentados na Seção 4, que trata dos procedimentos metodológicos do presente estudo.

\section{FORMULAÇÃO E DESENVOLVIMENTO DAS HIPÓTESES DE PESQUISA}

Com base nos fundamentos da teoria contábil discutidos na Seção 2, é possível inferir que a prática do conservadorismo na elaboração da informação contábil tem relação com situações que podem ser caracterizadas como incentivos para que a administração atue nesse sentido e mais especificamente, que as condições contratuais - implícitas ou explícitas - e o risco de litigância são dois dos fatores determinantes mais relevantes para essa prática contábil.

Dadas as suas peculiaridades, a indústria bancária pode ser considerada como um ambiente privilegiado para o desenvolvimento de estudos sobre o tema, tendo em vista suas características de forte regulação e supervisão, a sua importância para o adequado funcionamento dos demais setores econômicos e o fato de ser um negócio que depende essencialmente da confiança que lhes atribuem os agentes econômicos superavitários (depositantes). Considerando esse contexto, é formulada a seguinte hipótese de pesquisa, a ser testada empiricamente:

H1 Os bancos brasileiros praticam conservadorismo condicional nos resultados contábeis.

Partindo desse contexto mais amplo de aplicabilidade dos preceitos teóricos do conservadorismo condicional ao sistema bancário brasileiro, o presente estudo se concentra mais especificamente em avaliar essa prática em situações de maior percepção de riscos, quando, presume-se, a administração das instituições financeiras têm incentivos para aumentar a credibilidade das informações produzidas, até como forma de se proteger de questionamentos e ações fiscalizadoras mais rígidas por parte do regulador. Considerando esse propósito, uma etapa importante consiste em definir "situações de maior percepção de risco" para as instituições que integram o sistema bancário.

O primeiro parâmetro adotado é o risco sistêmico, definido por Capelletto (2006) como o grau de incerteza existente no sistema, resultante de alterações no nível de risco de crédito, de taxa de juros e da taxa de câmbio - a crise bancária sistêmica consiste em um choque capaz de estressar, no conjunto ou isoladamente, esses riscos na maior parte das instituições que compõem o sistema. No Brasil, como exemplo de crise bancária sistêmica foi apontado por Capelletto (2006) o período de 1994 a 1999, quando a confiança do sistema foi abalada pelas quebras de uma série de instituições importantes, como os bancos Econômico, Nacional e Bamerindus, bem como pelo esgotamento do modelo de bancos estaduais.

Mais recentemente, a crise financeira global de 2008, que surgiu no mercado de crédito imobiliário dos Estados Unidos da América (EUA) e atingiu seu ápice com a quebra do Lehman Brothers, espraiou-se por todos os mercados financeiros, em razão da influência do mercado norte-americano no sistema financeiro global. Os reflexos da crise econômica europeia, em sequência à crise dos subprime, também tem seu aspecto de risco bancário sistêmico, notado particularmente em mercados como o grego e o espanhol. As causas vão desde o fato de alguns bancos carregarem em suas carteiras volumes expressivos de títulos de 
emissores soberanos com reconhecida dificuldade de resgate, bem como pela constatação de bolhas imobiliárias. Dada a característica de interligação dos mercados, é natural que os problemas verificados nas indústrias bancárias norte-americana e europeia sejam refletidos, de alguma forma, no mercado brasileiro. Ademais, os casos de fraudes contábeis identificadas nos bancos Panamericano e Cruzeiro do Sul, em 2010 e 2012, respectivamente, reforçam a percepção de risco no mercado local.

Considerando, portanto, a premissa de que o risco sistêmico caracteriza o momento em que os bancos estão expostos a situações de maior percepção de risco e que há incentivos, nessas ocasiões, para o conservadorismo contábil, formula-se a seguinte hipótese de pesquisa:

$\mathbf{H}_{2 \mathrm{~A}}$ Os bancos brasileiros praticam maior conservadorismo condicional nos resultados contábeis nos momentos caracterizados como de risco sistêmico.

O segundo parâmetro considerado como referência para "situação de maior percepção de risco" é o nível de capitalização de cada banco. Se no caso do risco sistêmico, a medida se dá em relação ao conjunto das instituições, nesse caso há uma avaliação de cada banco em particular. Degryse, Elahi e Penas (2012) relacionam o nível de capitalização das instituições ao risco sistêmico, ao afirmarem que o impacto do contágio no sistema financeiro é atenuado quando o setor bancário é mais líquido e mais capitalizado. Entendimento equivalente é exposto por Berger et al. (2008), ao destacarem que os requerimentos regulatórios de capital têm o propósito de proteger a economia de externalidades negativas causadas por quebras bancárias, tendo em vista o risco sistêmico.

De acordo com Tapia et al. (2011), o pressuposto é que, quando o nível de capitalização do banco diminui, a preocupação dos reguladores se intensifica, levando ao aumento da percepção do risco de quebra do banco, sendo que essa preocupação tende a se verificar também por parte dos investidores e da mídia especializada. Em síntese, bancos com menor margem de capital não apenas estariam expostos a maior risco de responsabilização como também a maiores pressões por parte do supervisor bancário.

Assim, partindo do pressuposto de que quando menor for o nível de capitalização da instituição, maior a percepção de risco por parte dos agentes econômicos, e do supervisor em particular, o que deve se traduzir em maior demanda por conservadorismo na produção da informação contábil, formula-se a seguinte hipótese de pesquisa:

H2B Há uma relação negativa entre o nível de capitalização dos bancos brasileiros e a prática do conservadorismo condicional nos resultados contábeis.

A título de ressalva, é importante destacar que, não obstante os aspectos teóricos observados na formulação dessas hipóteses, em que situações de maior percepção de risco podem funcionar como incentivos para a administração praticar o conservadorismo na elaboração das informações financeiras, essas mesmas variáveis podem funcionar como incentivos para escolhas contábeis mais agressivas, com o propósito de demonstrar uma situação mais favorável e assim evitar o escrutínio dos agentes econômicos, e principalmente dos reguladores bancários. Essa dualidade funciona como um elemento adicional a fomentar a presente investigação, aumentando a importância de se esclarecer qual comportamento é mais aplicável à realidade praticada no sistema bancário brasileiro.

\section{MÉTODOS E PROCEDIMENTOS DA PESQUISA}

\subsection{População, Amostra e Coleta de Dados}

Para a realização dos testes empíricos foram utilizados dados das Informações Financeiras Trimestrais dos bancos comerciais, bancos múltiplos e caixas econômicas, integrantes do Sistema Financeiro Nacional (SFN), considerando o período entre 2001 e 2010. Inicialmente, 224 instituições aos parâmetros estabelecidos e representam a população objeto 
de estudo. Os dados contábeis utilizados são obtidos diretamente na página do $\mathrm{BCB}$ na internet.

\subsection{Especificação do Modelo e Parâmetros de Análise}

Seguindo Brito, Lopes e Coelho (2008), Nichols, Wahlen e Wieland (2009), Lima, Fonseca e Brito (2009) e Tapia et al. (2011), é utilizado o modelo de componentes transitórios do lucro, desenvolvido por Basu (1997) e ampliado por Ball e Shivakumar (2005). Em sua versão básica, o modelo desenvolvido para avaliar o conservadorismo condicional por meio da transitoriedade do lucro tem a seguinte especificação:

$$
\Delta L L_{i t}=\alpha_{0}+\alpha_{1} D \Delta L L_{i t-1}+\alpha_{2} \Delta L L_{i t-1}+\alpha_{3}\left(D \Delta L L_{i t-1} * \Delta L L_{i t-1}\right)+\varepsilon_{i t}
$$

em que: $\boldsymbol{\Delta} \boldsymbol{L} \boldsymbol{L}$ corresponde à variação do lucro líquido, em base anualizada, apurado trimestralmente, ponderado pelos ativos totais do início do período; $\boldsymbol{D} \boldsymbol{\Delta} \boldsymbol{L} \boldsymbol{L}$ é uma variável dummy, que assume valor 1 quando $\boldsymbol{\Delta} \boldsymbol{L} \boldsymbol{L}$ é negativa e 0 para os demais; e $\varepsilon$ é o termo de erro com a premissa de distribuição normal e variância constante.

Sob a condição de conservadorismo condicional no resultado contábil, a tempestividade no reconhecimento de ganhos e perdas deve ser assimétrica. É esperado que as perdas econômicas sejam reconhecidas tempestivamente, implicando que variações negativas no resultado sejam mais transitórias, ou seja, que o sinal do coeficiente $\alpha_{3}$ seja negativo. Para o coeficiente relativo aos ganhos econômicos, $\alpha_{2}$, há dois tipos de previsão. Para Nichols, Wahlen e Wieland (2009) e Tapia et al. (2011), é esperado que o reconhecimento dos ganhos econômicos seja diferido, razão pela qual variações positivas no resultado contábil devem ser mais persistentes, implicando em sinal positivo para o coeficiente $\alpha_{2}$. Com o mesmo argumento em relação ao diferimento dos ganhos econômicos, Ball e Shivakumar (2005) esperam que o coeficiente $\alpha_{2}$ seja estatisticamente igual a zero, tendo como consequência que a soma dos coeficientes $\alpha_{2}$ e $\alpha_{3}$ seja menor que zero $\left(\alpha_{2}+\alpha_{3}<0\right)$. A confirmação da hipótese de pesquisa $\mathbf{H}_{1}$, que prevê o conservadorismo condicional nos resultados contábeis dos bancos brasileiros, é condicionada, portanto, à constatação de valores negativos para $\alpha_{3}$, combinados com valores estatisticamente nulos ou positivos para $\alpha_{2}$.

Para testar as hipóteses de pesquisa $\mathbf{H}_{2 \mathrm{~A}}$ e $\mathbf{H}_{2 \mathbf{B}}$, esse modelo básico é ampliado com a incorporação de variáveis representativas de situações de maior percepção de risco $(\boldsymbol{S P R})$, alternadamente. Para testar $\mathbf{H}_{2}$ A, considerando que a amostra compreende as informações trimestrais entre 2001 e 2010, foi definido que o período a partir do terceiro trimestre de 2008 pode ser caracterizado como de risco sistêmico $(\boldsymbol{R S})$. É o período em que eclodiu a crise de crédito dos subprime nos EUA e se espalhou pelos mercados financeiros globais, afetando o fluxo de crédito, inclusive no mercado brasileiro. Os efeitos dessa crise, em relação à confiança nos sistemas bancários, entenderam-se aos anos seguintes, até porque a ela seguiuse a crise europeia. No Brasil, outro fato relevante, a detecção das fraudes no Banco Panamericano contribuiu para o surgimento de dúvidas sobre a confiabilidade das informações contábeis dos bancos brasileiros. Em relação ao nível de capitalização dos bancos, necessário para testar a $\mathbf{H}_{2 \mathbf{B}}$, a variável é mensurada de duas formas: uma medida essencialmente contábil, dada pela relação entre o patrimônio líquido e os ativos totais (Cap); e outra que considera o risco dos ativos na apuração do parâmetro de capitalização, o Índice de Basileia (Bas).

O modelo também foi ampliado com a incorporação de variáveis que permitem o controle de fatores que possam influir na prática do conservadorismo condicional por parte dos bancos. Seguindo Nichols, Wahlen e Wieland (2009) e Tapia et al. (2011) os resultados são controlados em relação ao tamanho das instituições bancárias (Tam), para capturar as 
eventuais diferenças de comportamento em relação ao conservadorismo que sejam explicadas pelo porte dos bancos. Outro fator de controle incorporado é o tipo de instituição em função da origem do capital de controle - privado ou público $(\boldsymbol{P} \boldsymbol{u b})$. Isso se justifica pelo entendimento externado por Brito, Lopes e Coelho (2008) de que no Brasil há diferenças na exposição legal entre esses tipos de bancos, sendo natural que se observe diferenças entre esses grupos de instituição em relação ao conservadorismo contábil. A inserção dessas variáveis de controle faz-se necessária para assegurar a robustez das evidências obtidas para as variáveis de interesse.

Com isso, o modelo definido para os testes empíricos das hipóteses de pesquisa assume a seguinte forma:

$$
\begin{aligned}
& \Delta L L_{i t}=\alpha_{0}+\alpha_{1} D \Delta L L_{i t-1}+\alpha_{2} \Delta L L_{i t-1}+\alpha_{3}\left(D \Delta L L_{i t-1} * \Delta L L_{i t-1}\right)+\alpha_{4} S P R_{i t-1} \\
& \quad+\alpha_{5}\left(S P R_{i t-1} * D \Delta L L_{i t-1}\right)+\alpha_{6}\left(S P R_{i t-1} * \Delta L L_{i t-1}\right)+\alpha_{7}\left(S P R_{i t-1} * D \Delta L L_{i t-1} * \Delta L L_{i t-1}\right) \\
& \quad+\alpha_{8} \operatorname{Tam}_{i t-1}+\alpha_{9}\left(\operatorname{Tam}_{i t-1} * D \Delta L L_{i t-1}\right)+\alpha_{10}\left(\operatorname{Tam}_{i t-1} * \Delta L L_{i t-1}\right) \\
& \quad+\alpha_{11}\left(\operatorname{Tam}_{i t-1} * D \Delta L L_{i t-1} * \Delta L L_{i t-1}\right)+\alpha_{12} P u b_{i}+\alpha_{13}\left(P u b_{i} * D \Delta L L_{i t-1}\right) \\
& \quad+\alpha_{14}\left(P u b_{i} * \Delta L L_{i t-1}\right)+\alpha_{15}\left(P u b_{i} * D \Delta L L_{i t-1} * \Delta L L_{i t-1}\right)+u_{i t}
\end{aligned}
$$

em que: $\boldsymbol{S P R}$ corresponde à situação de percepção de risco, assumindo, alternadamente, as variáveis $\boldsymbol{R} \boldsymbol{S}$ (variável dummy que identifica momentos de risco sistêmico, sendo 1 para os períodos a partir do terceiro trimestre de 2008 e 0 para os demais), Cap (nível de capitalização do banco, pela relação entre o patrimônio líquido e os ativos totais do final do período) ou Bas (Índice de Basileia de cada instituição, apurado e divulgado pelo BCB em sua página na internet); Tam traduz o tamanho da instituição, apurado pelo logaritmo natural do total dos ativos deflacionados pela variação do IPCA; Pub é variável dummy para identificação dos bancos cujo capital de controle é estatal, assumindo 1 para os bancos públicos e 0 para os privados; e $\boldsymbol{u}$ é o termo de erro com a premissa de distribuição normal e variância constante.

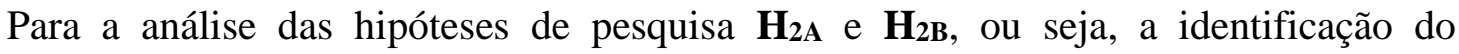
conservadorismo condicional praticado pelos bancos em situações de maior percepção de risco, os coeficientes de interesse são $\alpha_{6}$ e $\alpha_{7}$, guardando relação com as premissas relativas aos coeficientes $\alpha_{2}$ e $\alpha_{3}$, utilizadas na análise de $\mathbf{H}_{1}$. No que se refere ao sinal esperado sob a condição de conservadorismo, há uma distinção dependendo da variável assumida como proxy da situação de percepção de risco. Quando o modelo assume a variável $\boldsymbol{R S}$ (teste de $\mathbf{H}_{2 \mathrm{~A}}$ ), é esperado que $\alpha_{6}$ seja nulo ou positivo e $\alpha_{7}$ negativo, indicando que em momentos configurados como de risco sistêmico há um reconhecimento assimétrico de ganhos e perdas, com o reconhecimento mais tempestivo (menos persistência) das perdas econômicas (más notícias).

Nos casos em que o modelo assume as variáveis Cap ou Bas como proxies das situações de percepção de risco (teste de $\mathbf{H}_{2 \mathbf{B}}$ ), porém, os sinais esperados para os coeficientes $\alpha_{6}$ e $\alpha_{7}$ são negativo e positivo/nulo, respectivamente. Essa inversão se justifica pelo fato de as variáveis $\boldsymbol{C a p}$ e $\boldsymbol{B a s}$ serem contínuas e traduzirem maior percepção de risco quanto menor for o seu valor. Assim, se sob a condição de condição de conservadorismo é esperado que $\alpha_{2} \geq 0$ e $\alpha_{3}<0$, os efeitos das interações dos termos serão $\alpha_{6} \leq 0$ e $\alpha_{7}>0$. Isso significa que quanto menor o grau de capitalização, menor a persistência de variações negativas no resultado.

Em relação aos efeitos das variáveis de controle no conservadorismo condicional, representados pelos parâmetros $\alpha_{10}, \alpha_{11}, \alpha_{14}$ e $\alpha_{15}$, não foram formuladas previsões quanto ao seu comportamento. 


\subsection{Testes de Robustez}

Para assegurar a robustez das evidências empíricas apuradas, serão realizados: (i) testes de raízes unitárias, para verificar a condição de estacionariedade das séries não dicotômicas; (ii) teste de inflação de variância entre as variáveis independentes, para avaliar o risco de alto grau de multicolinearidade; (iii) teste de Chow, para avaliar a existência de efeitos individuais - premissa que justifica o uso dos dados em painel; (iv) teste de Hausman, para a definição do método de dados em painel a ser utilizado - modelos fixos ou aleatórios; (v) teste Durbin-Watson, para a avaliação da condição de ausência de autocorrelação nos resíduos; e (vi) procedimentos estatísticos SUR (PCSE) na estimação dos modelos, para mitigar o risco de heterocedasticidade nos resíduos.

\section{RESULTADOS}

Considerando os parâmetros de definição da população/amostra destacados na Seção 4.1, foram apuradas as variáveis necessárias à estimação do modelo (4.2). De forma a prevenir eventuais distorções na avaliação empírica em razão dos efeitos de valores extremos, foram excluídas inicialmente da base de dados algumas observações que distavam mais de cinco desvios padrões em relação à média. Considerando esses ajustes em relação aos outliers, os critérios de apuração da variável representativa do lucro líquido em bases anualizadas - período de quatro trimestres - e as definições das variáveis que compõem o modelo, com variações e valores defasados, foi construído um painel não balanceado com 5.915 observações referentes ao número de bancos/trimestres.

\subsection{Testes Preliminares: Estacionariedade das Séries e Multicolinearidade}

Como pré-condição para assegurar a robustez dos resultados decorrentes da aplicação do modelo (4.2), foram realizados inicialmente os testes Im, Pesaran e Shin de raízes unitárias, para verificar a estacionariedade das séries não dicotômicas. Os resultados, conforme Tabela 1, rejeitam a hipótese nula de presença de raiz unitária, com $p$-value igual a 0,0000 em todas elas, eliminando, assim, o risco de regressões espúrias.

Tabela 1: Testes de raízes unitárias Im, Pesaran e Schin (I.P.S) para as variáveis não dicotômicas.

\begin{tabular}{|c|c|c|c|c|c|}
\hline Variável & Teste I.P.S. & Variável & Teste I.P.S. & Variável & Teste I.P.S. \\
\hline$\Delta L L$ & $-76,9576$ & $\operatorname{Cap}^{*} \Delta L L$ & $-171,3360$ & Tam & $-30,2399$ \\
\hline$D \Delta L L * \Delta L L$ & $-31,8679$ & $\operatorname{Cap}^{*} D \Delta L L * \Delta L L$ & $-99,5255$ & $T a m * D \Delta L L$ & $-38,8187$ \\
\hline$\Delta L L * R S$ & $-91,8125$ & Bas & $-15,4087$ & $\operatorname{Tam}^{*} \Delta L L$ & $-24,1103$ \\
\hline$D \triangle L L * \triangle L L * R S$ & $-6,2024$ & $B a{ }^{*} D \triangle L L$ & $-32,5484$ & $T a m * D \Delta L L * \Delta L L$ & $-31,5164$ \\
\hline Cap & $-5,9990$ & $B a s^{*} \Delta L L$ & $-41,0836$ & $P u b^{*} \Delta L L$ & $-11,3280$ \\
\hline$C a{ }^{*} D \Delta L L$ & $-31,8822$ & $B a s^{*} D \Delta L L * \Delta L L$ & $-104,4980$ & $P u b^{*} D \Delta L L^{*} \Delta L L$ & $-8,4037$ \\
\hline
\end{tabular}

Em que: $\boldsymbol{\Delta} \boldsymbol{L} \boldsymbol{L}$ corresponde à variação do lucro líquido dos últimos doze meses, apurado trimestralmente, ponderado pelos ativos do início do período; D $\boldsymbol{\Delta} \boldsymbol{L} \boldsymbol{L}$ é uma variável dummy, que assume valor 1 quando $\boldsymbol{\Delta} \boldsymbol{L} \boldsymbol{L}$ é negativa e 0 para os demais; $\boldsymbol{R S}$ é variável dummy que identifica momentos de risco sistêmico, assumindo 1 para os períodos a partir do terceiro trimestre de 2008 e 0 para os demais; Cap representa o nível de capitalização do banco, medido pela relação entre o patrimônio líquido e os ativos totais do final do período; Bas corresponde ao Índice de Basileia de cada instituição, apurado e divulgado pelo BCB em sua página na internet; Tam traduz o tamanho da instituição, apurado pelo logaritmo natural do total dos ativos deflacionados pela variação do IPCA; e Pub é variável dummy para identificação dos bancos cujo capital de controle é estatal, assumindo 1 para os bancos públicos e 0 para os privados.

Também preliminarmente à aplicação do modelo, foi avaliado o risco de alto grau de multicolinearidade. Para esse diagnóstico, foi realizado o teste de inflação de variância entre as variáveis independentes, conforme Kennedy (1998) e Gujarati (2006). Na Tabela 2 são 
destacados os Fatores de Inflação de Variância (FIV) apurados a partir de regressões auxiliares entre cada variável independente (j-ésima) e os demais regressores do modelo.

Tabela 2: Resultados dos testes de inflação de variância entre as variáveis independentes.

\begin{tabular}{|c|c|c|c|c|c|c|}
\hline \multirow{2}{*}{ j-ésima variável } & \multicolumn{3}{|c|}{ Com controle do tamanho $(\mathrm{Tam})$} & \multicolumn{3}{|c|}{ Sem controle do tamanho $(\mathrm{Tam})$} \\
\hline & $S P R=R S$ & $S P R=C a p$ & $S P R=B a s$ & $S P R=R S$ & $S P R=C a p$ & $S P R=B a s$ \\
\hline$D \triangle L L$ & 50.5178 & 83.6260 & 69.5169 & 1.4476 & 2.6614 & 1.3191 \\
\hline$\triangle L L$ & 100.8980 & 170.9110 & 474.8338 & 1.3012 & 7.9690 & 1.3892 \\
\hline$D \Delta L L * \Delta L L$ & 107.7122 & 272.0348 & 297.0003 & 1.3026 & 6.0033 & 1.3722 \\
\hline$S P R$ & 3.1098 & 2.3625 & 3.3183 & 2.4700 & 1.8472 & 2.9910 \\
\hline$S P R * D \triangle L L$ & 3.5203 & 4.2407 & 4.0223 & 3.4038 & 3.0815 & 3.5943 \\
\hline$S P R^{*} \triangle L L$ & 4.0506 & 9.2910 & 4.6897 & 1.5124 & 7.2195 & 4.4613 \\
\hline$S P R * D \triangle L L * \triangle L L$ & 3.8137 & 7.5041 & 4.2533 & 3.7874 & 5.4486 & 4.0183 \\
\hline Tam & 2.3029 & 2.7297 & 2.7124 & & & \\
\hline $\operatorname{Tam} * D \triangle L L$ & 52.4054 & 72.6216 & 66.7512 & & & \\
\hline $\operatorname{Tam}^{*} \Delta L L$ & 98.7264 & 128.8494 & 449.2363 & & & \\
\hline $\operatorname{Tam}^{*} D \Delta L L * \Delta L L$ & 105.3408 & 224.3662 & 276.3958 & & & \\
\hline Pub & 2.8794 & 2.8787 & 2.8802 & 2.6900 & 2.7661 & 2.6787 \\
\hline$P u b^{*} D \triangle L L$ & 3.4534 & 3.4577 & 3.4540 & 3.2947 & 3.3646 & 3.2866 \\
\hline$P u b^{*} \Delta L L$ & 2.1076 & 2.1083 & 2.1107 & 2.0855 & 2.0823 & 2.0810 \\
\hline$P u b * D \Delta L L * \Delta L L$ & 2.5880 & 2.5870 & 2.5874 & 2.5764 & 2.5747 & 2.5725 \\
\hline
\end{tabular}

Em que: $\boldsymbol{\Delta} \boldsymbol{L} \boldsymbol{L}$ corresponde à variação do lucro líquido dos últimos doze meses, apurado trimestralmente, ponderado pelos ativos do início do período; $\boldsymbol{D} \boldsymbol{\Delta} \boldsymbol{L} \boldsymbol{L}$ é uma variável dummy, que assume valor 1 quando $\boldsymbol{\Delta} \boldsymbol{L} \boldsymbol{L}$ é negativa e 0 para os demais; $\boldsymbol{S P R}$ corresponde à situação de percepção de risco, assumindo, alternadamente, as variáveis $R S$, Cap e Bas; $\boldsymbol{R} S$ é variável dummy que identifica momentos de risco sistêmico, assumindo 1 para os períodos a partir do terceiro trimestre de 2008 e 0 para os demais; $\boldsymbol{C a p}$ representa o nível de capitalização do banco, medido pela relação entre o patrimônio líquido e os ativos totais do final do período; Bas corresponde ao Índice de Basileia de cada instituição, apurado e divulgado pelo BCB em sua página na internet; Tam traduz o tamanho da instituição, apurado pelo logaritmo natural do total dos ativos deflacionados pela variação do IPCA; e $\boldsymbol{P} \boldsymbol{u} \boldsymbol{b}$ é variável dummy para identificação dos bancos cujo capital de controle é estatal, assumindo 1 para os bancos públicos e 0 para os privados.

Considerando-se a regra objetiva mencionada em Kennedy (1998) e Gujarati (2006) de que há problemas sérios de multicolinearidade se algum dos FIV for maior que 10, os resultados evidenciados na Tabela 2, considerando o modelo (4.2) completo, indicam risco de alto grau de multicolinearidade. A elaboração de matriz de correlação (não incorporada por limitação de espaço) evidenciou que isso se justifica por alguns graus de correlação muito elevados: de 0,9773 entre $\boldsymbol{D} \boldsymbol{\Delta} \boldsymbol{L} \boldsymbol{L}$ e $\boldsymbol{T a m} * \boldsymbol{D} \boldsymbol{\Delta} \boldsymbol{L} \boldsymbol{L}$; de 0,9916 entre $\boldsymbol{\Delta} \boldsymbol{L} \boldsymbol{L}$ e $\boldsymbol{T a \boldsymbol { m }} * \boldsymbol{\Delta} \boldsymbol{L} \boldsymbol{L}$; e de 0,9879 entre $\boldsymbol{D} \boldsymbol{\Delta} \boldsymbol{L} \boldsymbol{L} * \boldsymbol{\Delta} \boldsymbol{L}$ e $\boldsymbol{T a m} * \boldsymbol{D} \boldsymbol{\Delta} \boldsymbol{L} \boldsymbol{L} * \boldsymbol{\Delta} \boldsymbol{L}$. Por essa razão, foram realizados testes adicionais com a exclusão do controle em relação tamanho das instituições (Tam), confirmando-se, nesse caso, que não se configura o risco de comprometimento da robustez das evidências empíricas em decorrência de problemas de multicolinearidade.

\subsection{Estimação do Modelo de Conservadorismo Condicional}

Tendo em vista que os testes apontaram o risco de alto grau de multicolinearidade no caso de se promover o controle em relação ao tamanho das instituições financeiras, a estimação do modelo (4.2) é realizada com uma versão mais sintética, controlando-se apenas 
para eventuais diferenças de comportamento pelo fato de o banco ser estatal ou privado.

$\mathrm{Na}$ Tabela 3 são apresentados os resultados da estimação do modelo para testar a hipótese de conservadorismo condicional nos resultados contábeis dos bancos brasileiros, especialmente em situações de maior percepção de risco. São consolidadas diferentes combinações de especificações do modelo, assumindo o risco sistêmico $(\boldsymbol{R S})$, o nível de capitalização (Cap) e o Índice de Basileia (Bas) como proxies para a identificação das situações de maior percepção de risco $(\boldsymbol{S P R})$. Os resultados foram obtidos com o uso de dados em painel com efeitos fixos seccionais e duplos efeitos fixos - seccionais e temporais. Cabe ressaltar que no caso de utilização de $\boldsymbol{R S}$ como proxy da situação de percepção de risco não é possível utilizar o método de duplos efeitos fixos, pois a própria variável já é uma medida de controle temporal do tipo dummy.

Tabela 3: Resultados de regressão com efeitos fixos seccionais e duplos efeitos fixos para identificação do conservadorismo condicional em bancos em situações de percepção de risco.

\begin{tabular}{|c|c|c|c|c|c|}
\hline $\begin{array}{r}\Delta L L \\
+\alpha_{5}(S P \\
+\alpha_{8} P u b_{i}+\end{array}$ & $\begin{array}{l}+\alpha_{1} D \Delta L L \\
\left.D \Delta L L_{i t-1}\right) \\
b_{i}^{*} D \Delta L L_{i t}\end{array}$ & $\begin{array}{r}\text { Modelo t } \\
+\alpha_{2} \Delta L L_{i t-1} \\
\left(S P R_{i t-1} * \Delta\right. \\
\alpha_{10}\left(P u b_{i}^{*}\right.\end{array}$ & $\begin{array}{l}\left(D \Delta L L_{i t-1}\right. \\
\left.{ }_{1}\right)+\alpha_{7}(S P \\
\left.{ }_{t-1}\right)+\alpha_{11}(P t\end{array}$ & $\begin{array}{l}\left.L_{i t-1}\right)+\alpha_{4} S \\
* D \Delta L L_{i t-1} \\
D \Delta L L_{i t-1}\end{array}$ & $\begin{array}{l}-1 \\
\left.L_{i t-1}\right) \\
i t-1)+\varepsilon_{i t}\end{array}$ \\
\hline Coeficiente & $\begin{array}{l}\text { EF Secc. } \\
S P R=R S\end{array}$ & $\begin{array}{c}\text { EF Secc. } \\
S P R=\text { Cap }\end{array}$ & $\begin{array}{c}\text { EF Secc. } \\
S P R=\text { Bas }\end{array}$ & $\begin{array}{c}\text { Duplo EF } \\
S P R=C a p\end{array}$ & $\begin{array}{c}\text { Duplo EF } \\
S P R=B a s\end{array}$ \\
\hline$\alpha_{0}$ & $\begin{array}{r}0,0036 \\
(0,3873)\end{array}$ & $\begin{array}{c}0,0024 \\
(0,7651)\end{array}$ & $\begin{array}{r}0,0029 \\
(0,4949)\end{array}$ & $\begin{array}{c}0,0014 \\
(0,8614)\end{array}$ & $\begin{array}{r}0,0023 \\
(0,5519)\end{array}$ \\
\hline$\alpha_{1}$ & $\begin{array}{r}-0,0035 \\
(0,4342)\end{array}$ & $\begin{array}{r}0,0019 \\
(0,7293)\end{array}$ & $\begin{array}{l}-0,0021 \\
(0,6500)\end{array}$ & $\begin{array}{r}0,0024 \\
(0,6686)\end{array}$ & $\begin{array}{r}-0,0020 \\
(0,6600)\end{array}$ \\
\hline$\alpha_{2}$ & $\begin{array}{l}0,2451 * * \\
(0,0246)\end{array}$ & $\begin{array}{c}0,5503^{*} \\
(0,0629)\end{array}$ & $\begin{array}{l}0,3002 * * \\
(0,0149)\end{array}$ & $\begin{array}{c}0,5509^{*} \\
(0,0628)\end{array}$ & $\begin{array}{l}0,3048^{* *} \\
(0,0135)\end{array}$ \\
\hline$\alpha_{3}$ & $\begin{array}{l}-0,2613 * * \\
(0,0392)\end{array}$ & $\begin{array}{l}-0,8169 * * \\
(0,0129)\end{array}$ & $\begin{array}{l}-0,3423 * * \\
(0,0188)\end{array}$ & $\begin{array}{l}-0,8227 * * \\
(0,0126)\end{array}$ & $\begin{array}{l}-0,3500^{* * *} \\
(0,0163)\end{array}$ \\
\hline$\alpha_{4}$ & $\begin{array}{c}0,0016 \\
(0,7996)\end{array}$ & $\begin{array}{c}0,0018 \\
(0,9401)\end{array}$ & $\begin{array}{l}-0,0034 \\
(0,2469)\end{array}$ & $\begin{array}{c}0,0047 \\
(0,8440)\end{array}$ & $\begin{array}{c}-0,0013 \\
(0,6644)\end{array}$ \\
\hline$\alpha_{5}$ & $\begin{array}{c}-0,0011 \\
(0,9060)\end{array}$ & $\begin{array}{r}-0,0113 \\
(0,5944)\end{array}$ & $\begin{array}{c}0,0028 \\
(0,4259)\end{array}$ & $\begin{array}{l}-0,0126 \\
(0,5597)\end{array}$ & $\begin{array}{c}0,0011 \\
(0,7542)\end{array}$ \\
\hline$\alpha_{6}$ & $\begin{array}{c}-0,1792 \\
(0,4592)\end{array}$ & $\begin{array}{r}-0,7417 \\
(0,1763)\end{array}$ & $\begin{array}{c}-0,0664 \\
(0,3367)\end{array}$ & $\begin{array}{c}-0,7368 \\
(0,1791)\end{array}$ & $\begin{array}{r}-0,0824 \\
(0,2343)\end{array}$ \\
\hline$\alpha_{7}$ & $\begin{array}{r}0,1826 \\
(0,8161)\end{array}$ & $\begin{array}{l}1,6960 * * \\
(0,0271)\end{array}$ & $\begin{array}{r}0,1096 \\
(0,2447)\end{array}$ & $\begin{array}{l}1,6979 * * \\
(0,0274)\end{array}$ & $\begin{array}{r}0,1275 \\
(0,1806)\end{array}$ \\
\hline$\alpha_{8}$ & $\begin{array}{l}-0,0393 * * \\
(0,0346)\end{array}$ & $\begin{array}{l}-0,0384^{*} \\
(0,0571)\end{array}$ & $\begin{array}{l}-0,0361 * \\
(0,0525)\end{array}$ & $\begin{array}{l}-0,0378^{*} \\
(0,0559)\end{array}$ & $\begin{array}{l}-0,0360 * \\
(0,0542)\end{array}$ \\
\hline$\alpha_{9}$ & $\begin{array}{c}0,0041 \\
(0,4370)\end{array}$ & $\begin{array}{r}-0,0004 \\
(0,9416)\end{array}$ & $\begin{array}{c}0,0018 \\
(0,7267)\end{array}$ & $\begin{array}{l}-0,0013 \\
(0,8045)\end{array}$ & $\begin{array}{c}0,0024 \\
(0,6491)\end{array}$ \\
\hline$\alpha_{10}$ & $\begin{array}{c}0,5491 \\
(0,1526)\end{array}$ & $\begin{array}{c}0,2770 \\
(0,5278)\end{array}$ & $\begin{array}{r}0,4834 \\
(0,2102)\end{array}$ & $\begin{array}{c}0,2611 \\
(0,5711)\end{array}$ & $\begin{array}{c}0,5196 \\
(0,1972)\end{array}$ \\
\hline$\alpha_{11}$ & $\begin{array}{r}-0,5766 \\
(0,5367)\end{array}$ & $\begin{array}{r}-0,1958 \\
(0,8335)\end{array}$ & $\begin{array}{l}-0,4793 \\
(0,5989)\end{array}$ & $\begin{array}{l}-0,5440 \\
(0,7948)\end{array}$ & $\begin{array}{r}-0,6017 \\
(0,5257)\end{array}$ \\
\hline$\alpha_{2}+\alpha_{3}$ & $-0,0162$ & $-0,2666$ & $-0,0421$ & $-0,2718$ & $-0,0452$ \\
\hline$\alpha_{6}+\alpha_{7}$ & 0,0034 & 0,9543 & 0,0432 & 0,9611 & 0,0451 \\
\hline
\end{tabular}




\begin{tabular}{|c|c|c|c|c|c|}
\hline Coeficiente & $\begin{array}{l}\text { EF Secc. } \\
S P R=R S\end{array}$ & $\begin{array}{c}\text { EF Secc. } \\
S P R=C a p\end{array}$ & $\begin{array}{c}\text { EF Secc. } \\
S P R=\text { Bas }\end{array}$ & $\begin{array}{c}\text { Duplo EF } \\
S P R=C a p\end{array}$ & $\begin{array}{c}\text { Duplo EF } \\
S P R=B a s\end{array}$ \\
\hline $\mathrm{N}^{\mathrm{o}}$ bancos: & 205 & 204 & 202 & 204 & 202 \\
\hline $\mathrm{N}^{\circ}$ observações: & 5.915 & 5.749 & 5.724 & 5.749 & 5.724 \\
\hline$R^{2}$ & 0,1059 & 0,1268 & 0,1188 & 0,1344 & 0,1266 \\
\hline$R^{2}$ ajustado & 0,0726 & 0,0930 & 0,0849 & 0,0954 & 0,0874 \\
\hline Estatística DW & 1,3050 & 1,2533 & 1,2581 & 1,2590 & 1,2634 \\
\hline F Estatística & 3,1394 & 3,7550 & 3,5035 & 3,4437 & 3,2270 \\
\hline $\mathrm{F}$ (p-valor) & 0,0000 & 0,0000 & 1,2581 & 1,2590 & 1,2634 \\
\hline Teste Chow & 1,9323 & 1,9093 & 2,0045 & 2,1899 & 2,2895 \\
\hline Teste Hausman & 184,7122 & 225,4536 & 123,4074 & N/A & N/A \\
\hline Hausman (p-valor) & 0,0000 & 0,0000 & 0,0000 & N/A & N/A \\
\hline
\end{tabular}

Onde: $\boldsymbol{\Delta} \boldsymbol{L} \boldsymbol{L}$ corresponde à variação do lucro líquido dos últimos doze meses, apurado trimestralmente, ponderado pelos ativos do início do período; $\boldsymbol{D} \boldsymbol{\Delta} \boldsymbol{L} \boldsymbol{L}$ é uma variável dummy, que assume valor 1 quando $\boldsymbol{\Delta} \boldsymbol{L} \boldsymbol{L}$ é negativa e 0 para os demais; $\boldsymbol{S P R}$ corresponde à situação de percepção de risco, assumindo, alternadamente, as variáveis $R S$, Cap e Bas; $\boldsymbol{R S}$ é variável dummy que identifica momentos de risco sistêmico, assumindo 1 para os períodos a partir do terceiro trimestre de 2008 e 0 para os demais; Cap traduz o nível de capitalização do banco, medido pela relação entre o patrimônio líquido e os ativos totais do final do período; Bas corresponde ao Índice de Basileia de cada instituição, apurado e divulgado pelo BCB em sua página na internet; Tam traduz o tamanho da instituição, apurado pelo logaritmo natural do total dos ativos deflacionados pela variação do IPCA; e Pub é variável dummy para identificação dos bancos cujo capital de controle é estatal, assumindo 1 para os bancos públicos e 0 para os privados.

Nível de significância: *** $1 \%$; ** 5\%; *10\%. P-valores entre parênteses.

Dos resultados evidenciados na Tabela 3, merece destaque, inicialmente, o fato de que coeficiente $\alpha_{2}$ registrou valor positivo nas cinco combinações de testes, indicando que variações positivas no resultado contábil são persistentes, o que sugere o diferimento dos ganhos econômicos (as boas notícias). Por outro lado, em relação ao coeficiente $\alpha_{3}$ foi encontrado valor negativo e relevante em todos os testes, evidenciando que variações negativas no resultado contábil são mais transitórias, sugerindo que as perdas econômicas (as más notícias) são reconhecidas tempestivamente. Outra condição avaliada refere-se à soma dos coeficientes de interesse, confirmando a premissa de que $\alpha_{2}+\alpha_{3}<0$ em todas as cinco estimações realizadas.

A combinação dessas evidências confirma a maior persistência das variações positivas no resultado contábil e maior transitoriedade das variações negativas. Os resultados corroboram, portanto, a hipótese de pesquisa $\mathbf{H}_{1}$, permitindo constatar a prática do conservadorismo condicional nos resultados contábeis no âmbito da indústria bancária brasileira, ou seja, que há reconhecimento assimétrico de boas e más notícias, com o diferimento dos ganhos econômicos e reconhecimento mais tempestivo das perdas.

Para a análise específica das hipóteses de pesquisa relacionadas ao conservadorismo condicional dos resultados contábeis em situações de maior percepção de risco para as instituições bancárias, os coeficientes de interesse são $\alpha_{6}$ e $\alpha_{7}$. Para a hipótese $\mathbf{H}_{2 \mathrm{~A}}$, que prevê maior conservadorismo condicional nos momentos caracterizados como de risco sistêmico, o teste de interesse é aquele em que a variável $\boldsymbol{R S}$ assume a caracterização da situação de percepção de risco $(\boldsymbol{S P R})$. A confirmação da condição de conservadorismo nesse tipo de situação estaria condicionada a que o coeficiente $\alpha_{7}$ registrasse valor negativo e que $\alpha_{6}$ fosse positivo ou estatisticamente zero, guardando relação com o previsto em relação aos componentes $\alpha_{3}$ e $\alpha_{2}$, respectivamente. Os resultados em relação a esse modelo de interesse 
$(\boldsymbol{S P R}=\boldsymbol{R} \boldsymbol{S})$ revelaram, porém, que não há significância estatística nos coeficientes $\alpha_{6}$ e $\alpha_{7}$, não se confirmando, portanto, a expectativa de que nos momentos caracterizados como de risco sistêmico a assimetria no reconhecimento de boas e más notícias seja acentuada, o que evidenciaria um aumento do conservadorismo condicional.

Para testar a hipótese H2B, que prevê uma associação negativa entre o nível de capitalização dos bancos e a prática do conservadorismo condicional, a situação de percepção de risco assume as variáveis Cap ou Bas, alternadamente. De se ressaltar que, nesse caso, a condição de conservadorismo condicional é caracterizada por valores negativos ou nulos para $\alpha_{6}$ e positivos para $\alpha_{7}$. Isso se justifica pelo fato de que são variáveis contínuas e a situação de risco é inversa aos indicadores de capitalização, medidos pela participação do capital próprio em relação aos ativos totais ou pelo Índice de Basileia.

Os resultados dos modelos em que a proxy da situação de percepção de risco é definida a partir da variável Bas não evidenciaram significância estatística para os coeficientes $\alpha_{6}$ e $\alpha_{7}$, não se confirmando a hipótese que previa um maior conservadorismo condicional quando o Índice de Basileia das instituições bancárias fosse menor. Não foram encontradas evidências de reconhecimento assimétrico de ganhos e perdas econômicas associadas ao nível do Índice de Basileia dos bancos, tanto com o método de efeitos fixos seccionais quanto o de duplos efeitos fixos. Os sinais encontrados até foram os esperados e a soma dos coeficientes de interesse foi positiva, atendendo à condição de que $\alpha_{6}+\alpha_{7}>0$, mas a ausência de significância estatística para o coeficiente $\alpha_{7}$ impõe a rejeição da hipótese de pesquisa $\mathbf{H}_{2 \mathbf{B}}$.

Nos modelos em que a proxy da situação de percepção de risco é baseada na variável Cap, os resultados apurados demonstram que o coeficiente $\alpha_{6}$ não é estatisticamente diferente de zero, enquanto para $\alpha_{7}$ foi apurado valor positivo e estatisticamente significante, coerente com a premissa prevista na hipótese Н2в de que há relação negativa entre a prática do conservadorismo condicional e o nível de capitalização dos bancos. Adicionalmente, a soma desses coeficientes de interesse apresentam resultados positivos $\left(\alpha_{6}+\alpha_{7}>0\right)$, atendendo à outra condição para a confirmação da hipótese de conservadorismo condicional. As evidências obtidas, com efeitos fixos seccionais ou duplos efeitos fixos, demonstram que o reconhecimento mais tempestivo das perdas econômicas pode ser associado ao menor nível de participação do capital próprio na estrutura de capitais do banco.

Como síntese, a relação negativa entre o nível de capitalização dos bancos brasileiros e a prática do conservadorismo condicional nos resultados contábeis, prevista na hipótese H2B, só é confirmada ao se utilizar a variável Cap como proxy para a identificação de situação caracterizada como de maior percepção de risco e em relação ao reconhecimento mais tempestivo das más notícias.

Quanto ao controle realizado em relação ao conservadorismo condicional nos resultados contábeis, por tipo de origem do capital de controle dos bancos, a ausência de significância estatística nos coeficientes $\alpha_{10}$ e $\alpha_{11}$ não permite se associar uma eventual diferença nessa prática contábil ao fato de o banco ser público ou privado.

A comparação do conjunto desses resultados com os encontrados por Brito, Lopes e Coelho (2008), outro estudo que avaliou o conservadorismo condicional na indústria bancária brasileira, revela divergências substanciais. Eles não encontraram evidências de conservadorismo no conjunto das instituições e constataram que as instituições públicas são mais conservadoras ao reportar seus resultados que os bancos privados. No presente estudo, ao contrário, foi evidenciado o conservadorismo condicional no conjunto da indústria 
bancária e a inexistência de diferença de comportamento entre os bancos públicos e privados em relação a essa prática.

A razão para essa divergência de resultados pode ser a diferença na composição das amostras e a forma de apuração das variáveis dos dois estudos. Brito, Lopes e Coelho (2008) consideraram dados anuais das instituições que fazem parte dos grupamentos denominados Consolidados Bancários I e II, envolvendo os bancos comerciais, bancos múltiplos, caixas econômicas, bancos de investimentos, bancos de desenvolvimento e conglomerados, entre 1997 e 2007. No presente estudo foram utilizadas informações trimestrais (resultados anualizados, apurados trimestralmente), entre 2001 e 2010, dos bancos comerciais, bancos múltiplos e caixas econômicas, que apresentam características mais homogêneas entre si.

\subsection{Procedimentos para Assegurar a Robustez dos Testes}

Além dos testes de raízes unitárias e de multicolinearidade, destacados na Seção 5.1, outros procedimentos estatísticos foram adotados para assegurar a robustez das evidências empíricas encontradas. Para avaliar a existência de efeitos individuais, o que justifica o uso dos dados em painel, foi realizado o teste de Chow, conforme Baltagi (2008). De acordo com as estatísticas incorporadas na Tabela 3, foi rejeitada a hipótese nula de que os resultados apurados sem a consideração da heterogeneidade individual seriam apropriados, demonstrando a relevância da utilização dos dados em painel para o provimento de evidências com maior poder informacional, na aplicação dos modelos em questão.

Para a definição do método de dados em painel a ser utilizado, modelos fixos ou aleatórios, foi realizado o teste de Hausman para os três modelos com efeitos fixos seccionais, conforme estatísticas incorporadas na Tabela 3, não se rejeitando a hipótese nula de que os estimadores dos modelos de efeitos fixos e de efeitos aleatórios não diferem substancialmente é rejeitada, tornando imprópria a utilização do método com efeitos aleatórios. Para os modelos com duplo efeitos fixos não foi realizado o teste de Hausman pelo fato de que não é possível utilizar modelo com duplo efeitos aleatórios no caso de painel não balanceado, como é o caso.

Por fim, na aplicação dos modelos foi utilizado o método de efeitos fixos cross-section SUR (PCSE), de forma a: mitigar o risco de heterocedasticidade nos resíduos, não obstante a adoção do escalonamento das variáveis contábeis utilizadas pelos ativos totais; e contornar o problema de autocorrelação nos resíduos detectado nas estatísticas do teste Durbin-Watson, cujos valores constam da Tabela 3. A adoção do método SUR (PCSE) de dados em painel se justifica pelo propósito de gerar resultados robustos, mesmo na presença de autocorrelação e de heterocedasticidade nos resíduos.

\section{CONCLUSÕES}

Embora estudos sobre a prática do conservadorismo contábil sejam relativamente comuns, os que se concentram especificamente na indústria bancária são escassos - no Brasil, em particular. A associação dessa carência de pesquisas sobre o tema com a percepção de que o ambiente de forte regulação e supervisão pode funcionar como um incentivo ao conservadorismo na elaboração das informações financeiras dos bancos justifica a necessidade de uma investigação a respeito. A sucessão de crises e fraudes verificadas nos últimos anos envolvendo instituições financeiras, em escala global, reforça essa percepção.

Considerando esse contexto, este estudo teve por objetivo verificar se os resultados contábeis na indústria bancária brasileira registram evidências de conservadorismo condicional e, mais especificamente, se essa prática pode ser associada a situações de maior percepção de risco.

Os resultados confirmaram, preliminarmente, que as variações positivas no resultado contábil são persistentes, enquanto as variações negativas são mais transitórias. Assim, pode- 
se considerar a existência de assimetria no reconhecimento das boas e más notícias, com o diferimento dos ganhos econômicos e reconhecimento mais tempestivo das perdas; sugerindo a ocorrência de prática do conservadorismo condicional nos resultados contábeis dos bancos brasileiros.

A etapa seguinte dos testes consistiu em identificar se a prática do conservadorismo condicional dos resultados contábeis dos bancos brasileiros aumenta em situações de maior percepção de risco. Não foi confirmada a expectativa de que nos momentos de risco sistêmico a assimetria no reconhecimento das boas e más notícias seja acentuada. A mesma situação é verificada quando a proxy para situação de percepção de risco é o Índice de Basileia. Não foram encontradas evidências de reconhecimento assimétrico de ganhos e perdas associado ao nível do Índice de Basileia dos bancos.

Porém, quando se avalia a situação de risco através do nível de capitalização eminentemente contábil, foram obtidas evidências de reconhecimento mais tempestivo das perdas econômicas associadas ao menor nível de participação do capital próprio na estrutura de capitais dos bancos. Adicionalmente, verificou-se que não existe diferença significativa no comportamento conservador praticado pelos bancos públicos e privados no Brasil.

Como contribuição ao avanço da literatura, as evidências empíricas obtidas no presente estudo ampliam o conhecimento sobre o conservadorismo condicional na indústria bancária. Não foram identificadas pesquisas anteriores que tenham confirmado tal prática entre os bancos brasileiros. Adicionalmente, a realização de testes para confirmar se o conservadorismo condicional nos resultados bancários é mais acentuado em situações caracterizadas como de maior percepção de risco representa uma inovação em relação a outras pesquisas do gênero. Além de auxiliar na compreensão da qualidade das informações contábeis reportadas pelas instituições financeiras, os achados desta pesquisa podem contribuir para o desenvolvimento de normas e práticas prudenciais na atividade bancária brasileira.

\section{REFERÊNCIAS}

AHMED, A. S.; BILlingS, B. K.; MORTON, R. M.; HARRIS, M. S. The role of accounting conservatism in mitigating bondholder-shareholder conflicts over dividend policy and in reducing debt costs. The Accounting Review, v. 77, n. 4, p. 867-890, October 2002. GALE: A94132379.

ALMEIDA, J. E. F. de. Qualidade da informação contábil em ambiente competitivo. 2010. Tese (Doutorado em Ciências Contábeis) - Programa de Pós-Graduação em Ciências Contábeis da Universidade de São Paulo, São Paulo.

BALL, R.; SHIVAKUMAR, L. Earnings quality in UK private firms: comparative loss recognition timeliness. Journal of Accounting and Economics, v. 39, n. 1, p. 83-128, 2005. DOI:10.1016/j.jacceco.2004.04.001.

BALL, R.; KOTHARI, S. P.; ROBIN, A. The effect of international institutional factors on properties of accounting earnings. Journal of Accounting and Economics, v. 29, n. 1, p. 1-51, 2000. DOI: 10.1016/S0165-4101(00)00012-4.

BALTAGI, B. H. Econometric analysis of panel data. 4 ed. West Sussex, UK: John Wiley, 2008. 
BASU, S. The conservatism principle and the asymmetric timeliness of earnings. Journal of Accounting and Economics, n. 24, p. 3-37, 1997. DOI: 10.1016/S0165-4101(97)00014-1.

BEAVER, W. H.; RYAN, S. G. Biases and lags in book value and their effects on the ability of the book-to-market ratio to predict book return on equity. Journal of Accounting Research, v. 38, n. 1, p. 127-148, 2000.

BERGER, A.; DeYOUNG, R.; FLANNERY, M.; LEE, D.; OZTEKIN, O. How Do Large Banking Organizations Manage Their Capital Ratios? The Federal Reserve Bank of Kansas City. Research Working Papers, April 2008. Disponível em: <www.kc.frb.org/Publicat/RESWKPAP/PDF/RWP08-01.pdf>. Acesso em 21 Abr, 2012.

BRITO, G. A. S.; LOPES, A. B.; COELHO, A. C. D. Conservadorismo nos resultados contábeis de instituições financeiras estatais e privadas. In: ENANPAD, 32., 2008. Anais... Rio de Janeiro: Setembro, 2008.

CAPELLETTO, L. R. Mensuração do risco sistêmico no setor bancário com utilização de variáveis contábeis e econômicas. 259 p. Tese de doutorado (Programa de Pós-Graduação em Contabilidade - Universidade de São Paulo/USP). São Paulo, 2006.

COELHO, A. C.; LIMA, I. S. Qualidade informacional e conservadorismo nos resultados contábeis publicados no Brasil. Revista Contabilidade e Finanças, v. 18, n. 45, p. 38-49, set-dez 2007. DOI: 10.1590/S1519-70772007000400004.

COMITÊ DE PRONUNCIAMENTOS CONTÁBEIS (CPC). Pronunciamento conceitual básico: Estrutura conceitual para elaboração e divulgação de relatório contábil-financeiro. 2011. Disponível em: <http://www.cpc.org.br/pdf/CPC00_R1.pdf >. Acesso em: 15 Abr, 2012.

COSTA, F. M.; COSTA, A. C. O.; LOPES, A. B. Conservadorismo em cinco países da américa do sul. Revista Contabilidade \& Finanças, v. 17, n. 41, p. 7-20, mai/ago 2006. DOI: $10.1590 /$ S1519-70772006000200002.

DECHOW, P. M; GE, W.; SCHRAND, C. M. Understanding earnings quality: a review of proxies, their determinants and their consequences. Journal of Accounting and Economics. v. 50, n. 2-3, p. 344-401, dec. 2010. DOI:10.1016/j.jacceco.2010.09.001.

DEGRYSE, H.; ELAHI, M. A.; PENAS, M. F. Determinants of banking system fragility: a regional perspective. SSRN Working Papers, feb 2012. Disponível em: <http://ssrn.com/abstract=2005034>. Acesso em: 19 abr, 2012.

ERKENS, D.; SUBRAMANYAM, K. R.; ZHANG, J. Affiliated Banker on Board and Conservative Accounting. SSRN Working Papers, set 2011. Disponível em: <http://ssrn.com/abstract=1950016>. Acesso em: 7 mar, 2012.

GIVOLY, D.; HAYN, C. The changing time-series properties of earnings, cash flows and accruals: has financial reporting become more conservative? Journal of Accounting and Economics, n. 29, p. 287-320, Ago. 2000. DOI: 10.1016/S0165-4101(00)00024-0. 
GONZAGA, R. P.; COSTA, F. M. A relação entre o conservadorismo contábil e os conflitos entre acionistas controladores e minoritários sobre as políticas de dividendos nas empresas brasileiras listadas na Bovespa. Revista Contabilidade \& Finanças, USP, São Paulo, v. 20, n. 50, p. 95-109, maio/agosto 2009. DOI: 10.1590/S1519-70772009000200007.

GUJARATI, D. N. Econometria básica. 4 ed. São Paulo: Campus, 2006.

KAIZER, C. V. C.; NOSSA, S. N.; BAPTISTA, E. C. S.; TEIXEIRA, A. J. C. O impacto da regulamentação contábil sobre o conservadorismo nas empresas do setor elétrico do Brasil. In: Congresso Brasileiro de Contabilidade, 18., Gramado/RS, 24 a 28 de ago 2008. Anais..., 2008.

KENNEDY, P. A Guide to Econometrics. 4 ed. Cambridge: Mass, 1998.

LaFOND, R.; WATTS, R. L. The information role of conservatism. The Accounting Review, v. 83, p. 447-478, 2008. GALE: A178691198.

LAUX, C.; LEUZ, C. The crisis of fair-value accounting: market sense of the recent debate. Accounting, Organizations and Society. v. 34, n. 6-7, p. 826-834, nov. 2009. DOI: 10.1016/j.aos.2009.04.003.

LEVINE, R. The corporate governance of banks: a concise discussion of concepts and evidence. World Bank Policy Research Working Paper, n. 3404, 2004.

LIMA, G. A. S. F.; FONSECA, J. A. S.; BRITO, G. A. S. Conservadorismo nos resultados contábeis dos bancos em Portugal. In: Congresso USP de Controladoria e Contabilidade, 9., 2009, São Paulo. Anais... São Paulo: FEA/USP, 2009. CD-ROM.

LOPES, A. B. A Informação contábil e o mercado de capitais. São Paulo: Pioneira Thomson Learning, 2002.

MOREIRA, R. L.; COLAUTO, R. D.; AMARAL, H. F. Conservadorismo condicional: estudo a partir de variáveis econômicas. Revista Contabilidade \& Finanças, v. 21, n. 54, p. 64-84, set/dez 2010. DOI: 10.1590/S1519-70772010000300006.

NICHOLS, C. D.; WAHLEN, J. M.; WIELAND, M. M. Publicly traded versus privately held: implications for conditional conservatism in bank accounting. Review of Accounting Studies, v. 14, n. 1, p. 88-122, 2009. DOI: 10.1007/s11142-008-9082-3.

OWENS, E. Accounting conservatism, going-concern horizon, and earnings informativeness. SSRN Working Papers, June 2011. Disponível <http://papers.ssrn.com/sol3/papers.cfm?abstract_id=1869108>. Acesso em 13 Fev, 2012.

PAULO, E.; ANTUNES, M. T. P; FORMIGONI, H. Estudo sobre o conservadorismo nas companhias abertas e fechadas brasileiras. RAE Revista de Administração de Empresas, v. 48, n.3, p. 46-60, jul/set. 2008. DOI: 10.1590/S0034-75902008000300005.

SANTOS, L. S. R.; COSTA, F. M. Conservadorismo contábil e timeliness: evidências empíricas nas demonstrações contábeis nas empresas brasileiras com ADRs negociados na 
Bolsa de Nova Iorque. Revista Contabilidade \& Finanças, v. 19, n. 48, p. 27-36, set/dez. 2008. DOI: 10.1590/S1519-70772008000300003.

TAPIA, B. A.; SÁNCHEZ, C. B.; ALEMÁN, J. P.; FERNÁNDEZ, M. T. T. Conservadurismo del resultado y riesgo de litigio en el sector bancario. Revista Española de Financiación y Contabilidad (REFC), v. 40, n. 152, p. 556-585, 2011.

WATTS, R. L.; ZIMMERMAN, J.L. Positive accounting theory. New Jersey: Prentice Hall, 1986.

WATTS, R. L. Conservatism in accounting part I: explanations and implications. Accounting Horizons, v. 17, n. 3, p. 207-221, Sep. 2003-a. GALE: A110074310.

WATTS, R. L. Conservatism in accounting part II: evidence and research opportunities. Accounting Horizons, v. 17, n. 4, p. 287-301, Dec. 2003-b. GALE: A112211853. 